\title{
Influence of retirement on nonadherence to medication for hypertension and diabetes
}

\author{
Mika Kivimäki PhD, G. David Batty PhD, Mark Hamer PhD, Hermann Nabi PhD, Maarit Korhonen PhD, \\ Risto Huupponen PhD, Jaana Pentti MSc, Tuula Oksanen PhD, Ichiro Kawachi PhD, Marianna Virtanen PhD, \\ Hugo Westerlund PhD, Jussi Vahtera PhD
}

Competing interests: Mika Kivimäki has received grant funding from the United Kingdom Medical Research Council, the National Institutes of Health, the Finnish Work Environment Foundation and the UK Economic and Social Research Council. Maarit Korhonen works on a project funded by the Social Insurance Institution of Finland. Risto Huupponen has received grant funding from the Social Insurance Institution of Finland and the Academy of Finland. No other competing interests were declared.

This article has been peer reviewed.

Correspondence to:

Mika Kivimäki,

m.kivimaki@ucl.ac.uk

CMAJ 2013. DOI:10.1503 /cmaj.122010

\section{ABSTRACT}

Background: The extent to which common life transitions influence medication adherence among patients remains unknown. We examined whether retirement is associated with a change in adherence to medication in patients with hypertension or type 2 diabetes.

Methods: Participants in the Finnish Public Sector study were linked to national registers. We included data for the years 1994-2011. We identified and followed 3468 adult patients with hypertension and 412 adult patients with type 2 diabetes for medication adherence for the 3 years before their retirement and the 4 years after their retirement (mean follow-up $6.8 \mathrm{yr}$ ). Our primary outcome was proportion of patients with poor adherence to medication, which we defined as less than $40 \%$ of days covered by treatment. We determined these proportions before and after retirement using data from filled prescriptions.

Results: The preretirement prevalence of poor adherence to medication was $6 \%$ in men and women with hypertension, $2 \%$ in men with diabetes and $4 \%$ in women with diabetes. Among men, retirement was associated with an increased risk of poor adherence to both antihypertensive agents (odds ratio [OR] 1.32, $95 \%$ confidence interval $[\mathrm{Cl}] 1.03-1.68)$ and antidiabetic drugs (OR 2.40, 95\% Cl 1.374.20). Among women, an increased risk of poor adherence was seen only for antihypertensive agents (OR $1.25,95 \% \mathrm{Cl} 1.07-1.46$ ). Similar results were apparent for alternative definitions of poor adherence. Our results did not differ across strata of age, socioeconomic status or comorbidity.

Interpretation: We found a decline in adherence to medication after retirement among men and women with hypertension and men with type 2 diabetes. If these findings can be confirmed, we need randomized controlled trials to determine whether interventions to reduce poor adherence after retirement could improve clinical outcomes of treatments for hypertension and diabetes.
$\mathrm{C}$ ardiovascular diseases are the leading cause of death worldwide, and diabetes is projected to be in the top 4 most common causes of death in high-income countries by $2030 .^{1,2}$ Modern antihypertensive medications can substantially reduce the risk of vascular events, and antidiabetic drugs are effective in decreasing diabetes complications. ${ }^{3,4}$ Unfortunately, poor adherence to a medication regimen is common ${ }^{5-7}$ and substantially hampers the effectiveness of these therapies. ${ }^{8-10}$ Identifying factors that predict adherence is of importance to public health.

Much of the research on medication adherence has focused on patient demographic factors and medical history, characteristics of physicians and pharmacists, and facilitation or barrier creation by health care systems. ${ }^{11}$ In addition, several trials have been designed to increase adher- ence though informational, behavioural and motivational strategies and by simplifying dosing regimens. ${ }^{12,13}$ In contrast, surprisingly little is known about the extent to which common life transitions affect adherence to treatment. Retirement is a particularly relevant life transition, because it coincides with various changes in daily routines that potentially affect the continuity of treatment. In addition, retirement is associated with a perception of reduced symptoms of ill health, which might further increase the likelihood of neglecting to follow prescribed treatment regimens. ${ }^{14-16}$

We employed multiple repeat measurements of filled prescriptions for antihypertensive and antidiabetic medications, both before and after retirement, to examine whether retirement might increase nonadherence among patients with hypertension or type 2 diabetes. 


\section{Methods}

\section{Study population and design}

We used data from the Finnish Public Sector Study, which follwed a cohort of $151901 \mathrm{em}$ ployees of local government in 10 towns and 21 public hospitals. ${ }^{17}$ These employees cover a wide range of occupational groups, from city mayors to semiskilled cleaners, the largest groups being nurses and teachers. The sex and age distribution of the members of the cohort correspond to those of all Finnish public sector employees (75\% v. $77 \%$ women; mean age 44 v. 45 yr). A detailed description of the Finnish Public Sector Study and its context is provided in Appendix 1 (available at www.cmaj.ca/lookup/suppl/doi:10.1503 /cmaj.122012/-/DC1).

We linked the cohort members to national prescription and health registers from 1994 to 2011 through the unique personal identification codes assigned to all permanent residents of Finland. Data linkage to registers was successful for all members of the cohort. This study was approved by the ethics committee of the Hospital District of Helsinki and Uusimaa.

\section{Assessment of retirement}

Data on retirement were obtained from electronic records of the Finnish Centre for Pensions. All gainful employment is insured in a pension scheme and accrues a pension, and the centre coordinates all earnings-related pensions for permanent residents of Finland. These records provided virtually complete retirement data for all participants. We obtained the dates at which all participants started to receive old-age or disability pension and their ages at retirement from Jan. 1, 1996, to Dec. 31, 2010, irrespective of the participants' workplace before retirement.

\section{Case definition for hypertension and type 2 diabetes}

Finnish National Health Insurance, coordinated by the Social Insurance Institution, covers all permanent residents of Finland and provides special reimbursement for additional costs associated with many chronic diseases, including hypertension and type 2 diabetes. Participants with hypertension or type 2 diabetes who required continuous medication were identified from the Social Insurance Institution Drug Reimbursement Register. This register contains data on all patients who have been granted reimbursement for medications in Finland, including antihypertensive and antidiabetic drugs, with the date on which the permission was granted (diagnostic details in Appendix 2, available at available at www.cmaj.ca/lookup /suppl/doi:10.1503/cmaj.122012/-/DC1).
Assessment of adherence to treatment

At the time of the study, all prescriptions were written by a physician. The Social Insurance Institution reimbursed $70 \%-100 \%$ of the costs of antihypertensive and antidiabetic drugs for patients granted special reimbursement, including the participants of the present study. We followed participants for adherence to treatment from 3 years before their retirement to up to 4 years after (the observation period). We used days covered by filled prescriptions to assess adherence to treatment, a valid measure of medical adherence in a closed pharmacy system, such as in Finland..$^{18}$ We defined poor medication adherence as less than $40 \%$ of days covered by treatment; we performed subsidiary analyses with alternative cut-offs of $20 \%, 30 \%, 50 \%$, $60 \%, 70 \%$ and $80 \% .^{10,19,20}$

We obtained data on all filled prescriptions of antihypertensive and antidiabetic drugs reimbursed to participants between Jan. 1, 1994, and Dec. 31, 2011, from the Social Insurance Institution Drug Prescription Register. This register covers the entire population but excludes prescriptions filled during stays in hospital. The World Health Organization Anatomic Therapeutic Chemical classification codes for antihypertensive medication were $\mathrm{C} 02$ (antihypertensives), $\mathrm{C} 03$ (diuretics), $\mathrm{C} 07$ ( $\beta$-blockers), C08 (calciumchannel blockers) and C09 (agents acting on the rennin-angiotensin system); the codes for antidiabetic medication were A10A (insulins and analogues), A10B (blood glucose-lowering drugs, excluding insulins) and A10X (other drugs used in diabetes). ${ }^{21}$ We used a validated method, based on defined daily doses dispensed, to calculate the number of days for which patients had medication available at each year of follow-up (Appendix 2). ${ }^{18}$

\section{Other variables}

Preretirement covariates included sex, age at retirement, socioeconomic status, depression and cardiovascular comorbidity. We obtained data on sex and socioeconomic status (i.e., manual v. nonmanual labour) from the employers' registers. An additional indicator for socioeconomic status was size of residence $\left(<80 \mathrm{v}\right.$. $\left.\geq 80 \mathrm{~m}^{2}\right)$, obtained from the Population Register Centre. We used the Finnish Hospital Discharge Register and the Social Insurance Institution registers to determine depression status (Appendix 2) and comorbid cardiovascular disease (at least 1 of coronary artery disease, coronary insufficiency, cardiac arrhythmia or cerebrovascular disease). Validation studies show the Finnish Hospital Discharge register to contain about $95 \%$ of all discharges, and records are correct in at least $95 \%$ of the dis- 


\begin{tabular}{|c|c|c|}
\hline \multirow[b]{2}{*}{ Characteristic } & \multicolumn{2}{|c|}{ No. $(\%) *$} \\
\hline & $\begin{array}{l}\text { Patients with } \\
\text { hypertension } \\
\quad(n=3468)\end{array}$ & $\begin{array}{l}\text { Patients with } \\
\text { type } 2 \text { diabetes } \\
\quad(n=412)\end{array}$ \\
\hline Follow-up, yr, mean \pm SD & $6.8 \pm 0.1$ & $6.7 \pm 0.3$ \\
\hline \multicolumn{3}{|l|}{ Sex } \\
\hline Male & $981(28.3)$ & $179(43.4)$ \\
\hline Female & $2487(71.7)$ & $233(56.6)$ \\
\hline \multicolumn{3}{|l|}{ Age at retirement, yr } \\
\hline$<62$ & $1900(54.8)$ & $203(49.3)$ \\
\hline$\geq 62$ & $1568(45.2)$ & $209(50.7)$ \\
\hline \multicolumn{3}{|l|}{ Occupational group } \\
\hline Nonmanual labour & $2317(67.0)$ & $252(61.2)$ \\
\hline Manual labour & $1144(33.0)$ & $159(38.8)$ \\
\hline \multicolumn{3}{|l|}{ Size of residence, $\mathrm{m}^{2}$} \\
\hline$<80$ & $1673(48.2)$ & $207(50.2)$ \\
\hline$\geq 80$ & $1795(51.8)$ & $205(49.8)$ \\
\hline \multicolumn{3}{|l|}{ Type of retirement } \\
\hline Statutory & $2337(67.4)$ & $249(60.4)$ \\
\hline For health reasons & $1131(32.6)$ & $163(39.6)$ \\
\hline \multicolumn{3}{|l|}{ Depression } \\
\hline No & $2873(82.8)$ & $349(84.7)$ \\
\hline Yes & $595(17.2)$ & $63(15.3)$ \\
\hline \multicolumn{3}{|l|}{ Comorbid CVDt } \\
\hline No & $3029(87.3)$ & $343(83.3)$ \\
\hline Yes & $439(12.7)$ & $69(16.7)$ \\
\hline \multicolumn{3}{|c|}{$\begin{array}{l}\text { Note: } \mathrm{CVD}=\text { cardiovascular disease, } \mathrm{SD}=\text { standard deviation. } \\
\text { *Unless otherwise indicated. } \\
\text { tCoronary insufficiency, coronary heart disease, cardiac arrhythmia and cerebrovascular } \\
\text { disease. }\end{array}$} \\
\hline
\end{tabular}

Table 2: Rates of poor medication adherence among study participants before and after retirement

\begin{tabular}{|c|c|c|c|}
\hline \multirow[b]{2}{*}{ Population } & \multicolumn{2}{|c|}{ Poor adherence, \%* } & \multirow[b]{2}{*}{$\begin{array}{l}\text { Adjustedt OR } \\
\qquad(95 \% \mathrm{Cl})\end{array}$} \\
\hline & $\begin{array}{l}\text { Before } \\
\text { retirement }\end{array}$ & $\begin{array}{c}\text { After } \\
\text { retirement }\end{array}$ & \\
\hline \multicolumn{4}{|c|}{$\begin{array}{l}\text { Patients with } \\
\text { hypertension }\end{array}$} \\
\hline Men & 5.6 & 7.2 & $1.32(1.03-1.68)$ \\
\hline Women & 6.1 & 7.5 & $1.25(1.07-1.46)$ \\
\hline \multicolumn{4}{|c|}{$\begin{array}{l}\text { Patients with } \\
\text { type } 2 \text { diabetes }\end{array}$} \\
\hline Men & 2.3 & 5.2 & $2.40(1.37-4.20)$ \\
\hline Women & 3.8 & 4.2 & $1.11(0.62-1.98)$ \\
\hline \multicolumn{4}{|c|}{$\begin{array}{l}\text { Note: } \mathrm{Cl}=\text { confidence interval, } \mathrm{OR}=\text { odds ratio. } \\
\text { *Defined as less than } 40 \% \text { of days covered by treatment. } \\
\text { tRepeated measures regression with generalized estimating equation adjusted for sex, age } \\
\text { at retirement and calendar year. }\end{array}$} \\
\hline
\end{tabular}

charges compared with the corresponding medical records. ${ }^{22,23}$ Dates of death were obtained from the Finnish Causes of Death Register, which has received high ranking with respect to its reliability and accuracy in international comparisons. ${ }^{24}$

\section{Statistical analysis}

We analyzed a 7-year observation period including the 3 years before and the 4 years after the date of retirement. Periods during which participants stayed in hospital were excluded from follow-up. Participants were censored at death. We stratified data by sex and performed analyses separately for poor adherence in relation to hypertension and diabetes medications. The participants who received treatment for both hypertension and diabetes were included in both sets of analyses. We calculated annual prevalence estimates and prevalence ratios of poor medication adherence and their $95 \%$ confidence intervals (CIs) using a repeated-measures logbinomial regression with the generalized estimating equation (GEE) method and autoregressive correlation structure. GEE takes into account the intraindividual correlation between measurements and is not sensitive to missing measurements. ${ }^{25}$ We used an interrupted time series design within the time series analysis to model the mean prevalence of medication adherence before and after retirement. We assigned a weight of 0.33 for each of the 3 preretirement years of follow-up and a weight of 0.25 for each of the 4 postretirement years. We computed odds ratios (ORs) and their 95\% CIs for postretirement adherence compared with preretirement adherence. We adjusted the models for age at retirement and, to eliminate period effects, for calendar year.

To examine whether there were differences in the associations according to various subgroups (ie, by age group, socioeconomic status, type of retirement [statutory v. for ill health], depression and cardiovascular comorbidity), we calculated the prevalence ratio of medication adherence after retirement compared with that before retirement from models including the subgroup, time, calendar year, age at retirement and the interaction term "subgroup characteristic $\times$ time."

We performed all statistical analyses using SAS 9.2.

\section{Results}

We identified 25535 people who retired between 1996 and 2010, 21052 of whom were alive at least 1 year after their retirement and were included in our analyses. Complete prescription data were available for all included participants. 
Of the 21052 participants, 3889 had hypertension before their retirement, and 611 had type 2 diabetes before their retirement. We only included patients with hypertension $(n=3468)$ or type 2 diabetes $(n=412)$ whose diagnoses were made before the start of our observation period; thus, we excluded 421 patients with hypertension and 199 patients with diabetes whose diagnoses were made after the start of our observation period.

Of the 3880 included participants, 2720 $(70.1 \%)$ were female, corresponding the sex distribution of the overall cohort (Table 1). Median age at retirement for participants was 61 years (interquartile range 55-64 yr). The mean followup was 6.8 years for patients with hypertension and 6.7 years for patients with diabetes.

Among men with hypertension, the adjusted prevalence of poor adherence to antihypertensive medication was $5.6 \%$ during the 3 years of follow-up before their retirement and $7.2 \%$ during the 4 years of follow-up after their retirement (Table 2). The corresponding adjusted OR was 1.32 (95\% CI 1.03-1.68, postretirement v. preretirement). We saw a similar trend in relation to antidiabetic medication: the adjusted prevalence of poor adherence was $2.3 \%$ before retirement and $5.2 \%$ after retirement, with an adjusted OR of 2.40 (95\% CI 1.37-4.20). Among women, the ratio for poor adherence to antihypertensive medication was 1.25 (95\% CI 1.07-1.46), with a preretirement prevalence of poor adherence of $6.1 \%$ and a postretirement prevalence of $7.5 \%$. We saw no significant change in adherence in relation to antidiabetic medication for women before and after retirement.

More-detailed year-by-year trajectories of poor medication adherence, adjusted for age at retirement and calendar year, confirmed that the annual prevalence of poor adherence to antihypertensive medication was higher for each year of postretirement follow-up than for preretirement follow-up (Appendix 3, available at www.cmaj.ca/lookup/suppl/doi:10.1503/cmaj $.122012 /$-/DC1). For men, but not women, a similar pattern was seen for annual prevalences of poor adherence to antidiabetic medication.

Among men, we saw a postretirement increase in prevalence of poor adherence to antihy-

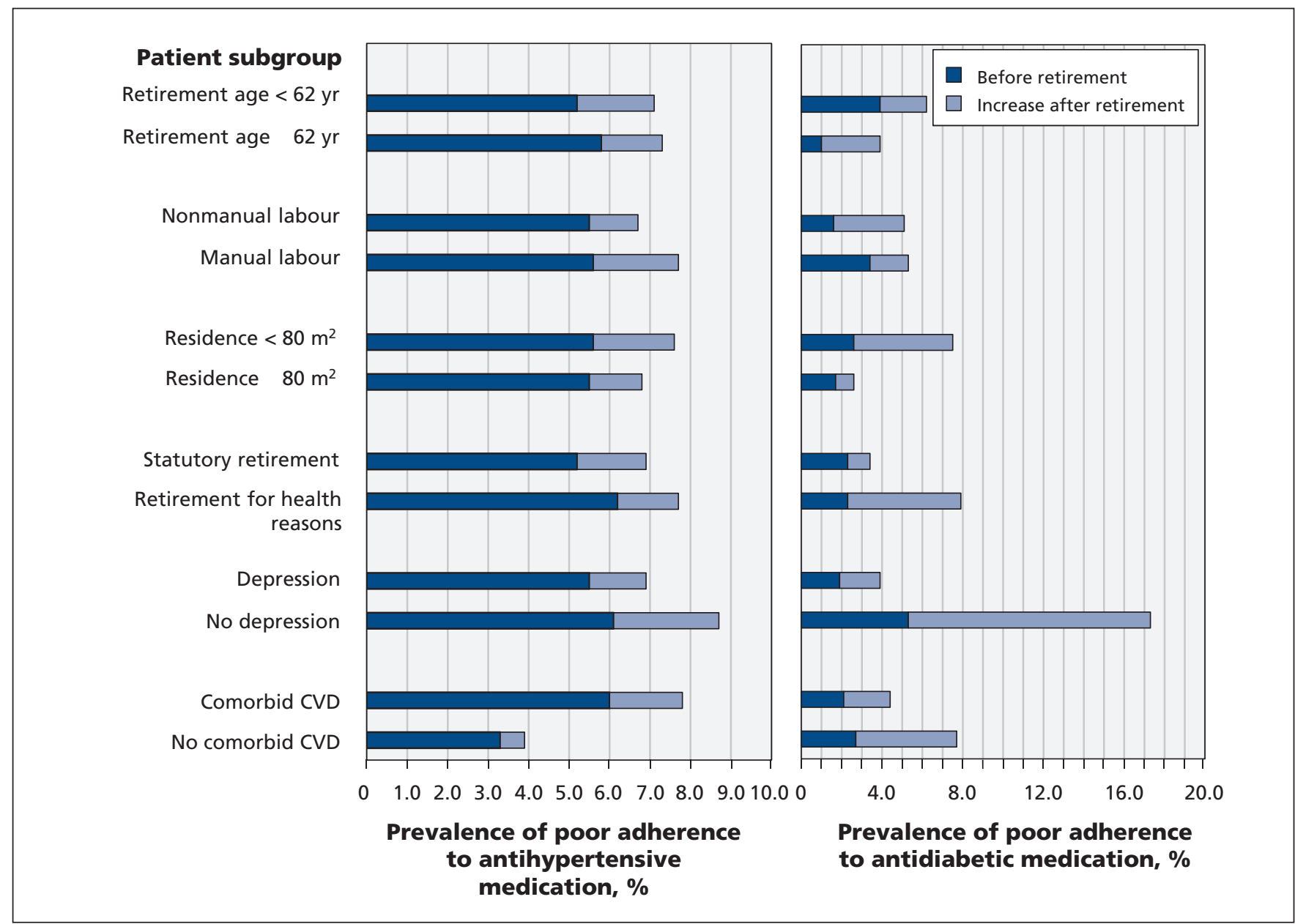

Figure 1: Prevalence of poor adherence to medication among men before and after retirement, by patient subgroup and type of drug. CVD = cardiovascular disease. 
pertensive and antidiabetic medications in younger and older employees, across occupational groups, sizes of residence and types of retirement, and among those with and without comorbidity (Figure 1 and Appendix 4, available at www.cmaj.ca/lookup/suppl/doi:10.1503/cmaj $.122012 /-/ D C 1)$. The results for women with hypertension were similar (Figure 2 and Appendix 4), with the exception that poor adherence did not increase substantially after retirement among those with comorbid cardiovascular conditions. Nonetheless, there was no statistical evidence to suggest that the postretirement increase in poor adherence would differ between subgroups (all $p$ for interaction $>0.07$ ).

Repeating our main analysis using alternative cut-offs for poor adherence showed postretirement increases in poor adherence among men and women with hypertension for all alternative definitions, ranging from less than $20 \%$ of days to less than $80 \%$ of days covered by treatment. For example, when poor adherence was defined as less than $80 \%$ of days covered by filled pre-

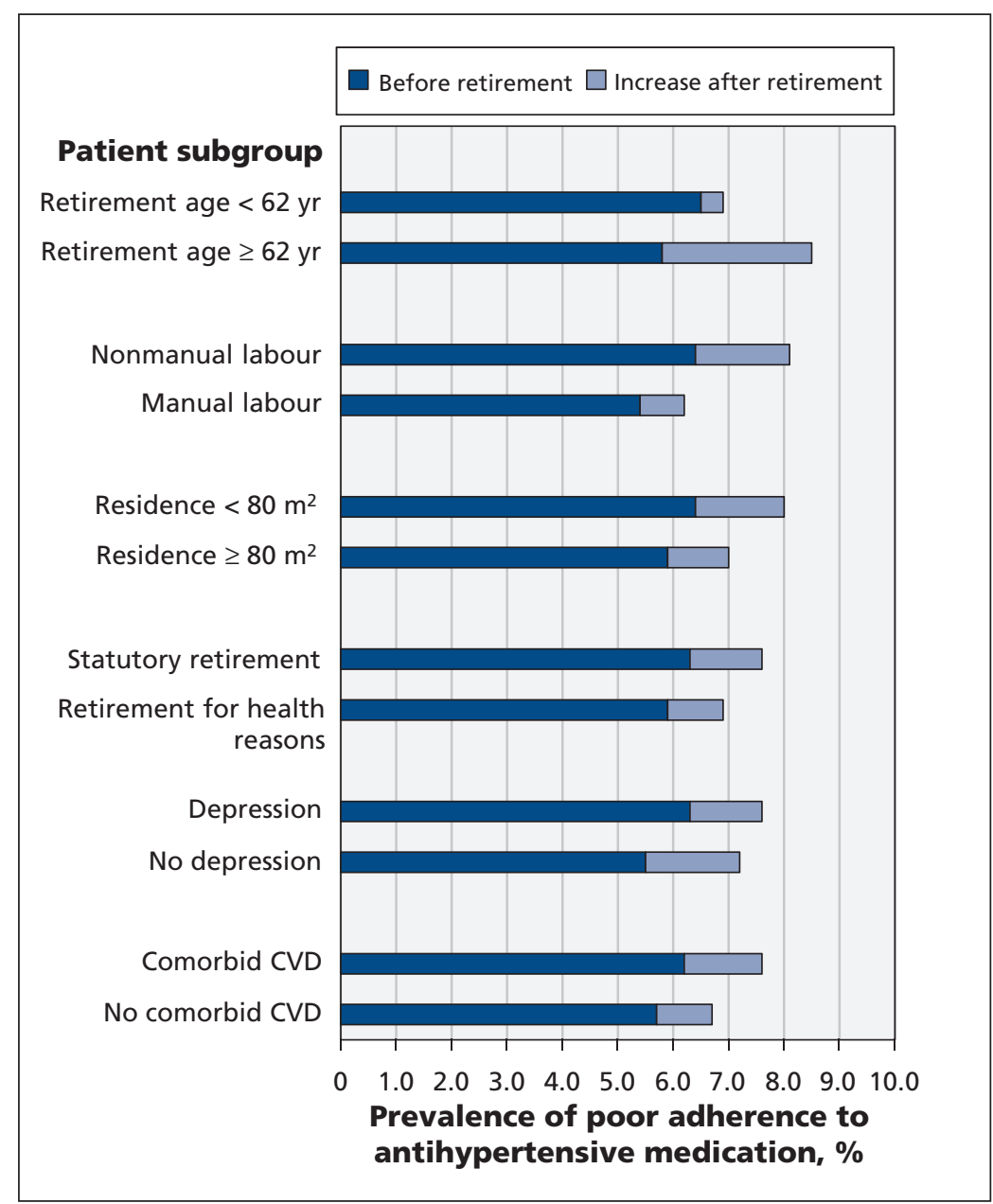

Figure 2: Prevalence of poor adherence to antihypertensive medication among women before and after retirement, by patient subgroup. CVD = cardiovascular disease. scriptions, adherence was $19.9 \%$ before retirement and $24.1 \%$ after retirement for men with hypertension (adjusted OR 1.29, 95\% CI 1.111.49) (Table 3). A postretirement increase in poor adherence was also seen in men with type 2 diabetes when poor adherence was defined as less than $20 \%, 30 \%, 40 \%$ or $50 \%$ of days covered by treatment.

\section{Interpretation}

For men and women with hypertension and men with type 2 diabetes, retirement was linked to 1.3- to 2.4-fold increases in poor medication adherence. We saw no significant difference in this adherence pattern between age groups, socioeconomic strata, or patients with and without depression or comorbid cardiovascular disease. These patterns suggest that our findings were robust and not limited to a specific subgroup. Our results were also robust when we used alternative definitions of poor adherence.

Major life changes other than retirement have previously been shown to be associated with a decline in medication adherence. ${ }^{26,27}$ The reasons for reduced postretirement adherence are not known. However, several recent studies have shown a long-term improvement in perceived health after statutory retirement. ${ }^{14-16}$ Given that hypertension and type 2 diabetes are often asymptomatic, a perception of reduced symptoms of ill health after retirement may result in a sense of false security encouraging reduced medication use. Other plausible explanations include the loss of the daily routines imposed by work leading to increased forgetfulness, and the transition from occupational to nonoccupational health care interrupting patients' interactions with their general practitioners, potentially affecting the continuity of drug treatments. Such an interruption could cause a temporary decline in adherence, although our year-by-year analysis suggests that the increase in poor adherence persisted for the entire postretirement follow-up period. Furthermore, retirement is related to a reduction in income, which might lead patients to prioritize other purchases over their medication. ${ }^{28}$ However, this explanation seems unlikely in the current context, because the postretirement increase in nonadherence was seen across socioeconomic strata. Indeed, costs related to antihypertensive and antidiabetic drugs are relatively low and, in Finland, filled prescriptions are mostly or fully reimbursed by national health insurance, similar to insurance schemes for older adults in other Scandinavian countries, the United Kingdom, the United States and Canada. 


\section{Strengths and limitations}

Finland and the other Scandinavian countries are particularly favourable settings for these kinds of studies, because they are under single universal prescription reimbursement systems with fully or nearly fully comprehensive prescription registers. ${ }^{11}$ This circumstance offers a rare possibility to monitor individual patient adherence to medication in day-to-day clinical practice. However, our results have some limitations.

This study did not include medical examinations. The diagnoses of hypertension and type 2 diabetes came from treating physicians and were confirmed by an external national committee granting special reimbursement for medication. Although pharmacy refill records are objective measures and collected routinely, they include only information on purchases and do not represent a measure of whether the patients actually took the medications. Thus, it is possible that we have slightly overestimated adherence. However, a substantial bias to relative differences in participants' adherence after retirement compared with before retirement is unlikely.

We determined the proportion of days covered by a medication for hypertension or diabetes using the daily defined doses, which is a valid, although not exact, method. ${ }^{18}$ Among patients with type 2 diabetes, adherence to injected insulin is, if anything, higher than adherence to medications taken orally. In this study, for example, the prevalence of poor adherence was $3.1 \%$ in men and $5.0 \%$ in women for medications taken orally, but only $1.6 \%$ among patients using insulin. Given that insulin treatment relates to a more advanced stage of the disease and thus is more common after retirement, this may have slightly masked the adverse effect of retirement on nonadherence among the participants with diabetes.

\section{Conclusion}

We found an increase in the prevalence of poor adherence to medication after retirement among men and women with hypertension and men with type 2 diabetes. These findings suggest that retirement may increase medication nonadherence, a timely issue given that the proportion of people aged 65 years or older is growing rapidly. Further research is needed to determine the generalizability of our findings across multiple settings and in other populations. In addition, randomized controlled trials are needed to determine whether interventions to tackle this issue would improve clinical outcomes of treatment.

\section{References}

1. Lozano R, Naghavi M, Foreman K, et al. Global and regional mortality from 235 causes of death for 20 age groups in 1990 and 2010: a systematic analysis for the Global Burden of
Disease Study 2010. [published erratum in Lancet 2013; 381:628. AlMazroa, Mohammad A (added); Memish, Ziad A (added)] Lancet 2012;380:2095-128.

2. Mathers CD, Loncar D. Projections of global mortality and burden of disease from 2002 to 2030. PLoS Med 2006;3:e442.

3. Turnbull F, Neal B, Ninomiya $T$, et al. Effects of different regimens to lower blood pressure on major cardiovascular events in older and younger adults: meta-analysis of randomised trials. BMJ 2008;336:1121-3

4. Effect of intensive blood-glucose control with metformin on

Table 3: Prevalence of poor medication adherence before and after retirement using alternative definitions of poor adherence

\begin{tabular}{|c|c|c|c|}
\hline \multirow[b]{2}{*}{ Days covered by treatment, $\%$} & \multicolumn{2}{|c|}{ Poor adherence, $\%$} & \multirow[b]{2}{*}{$\begin{array}{l}\text { Adjusted* OR } \\
(95 \% \mathrm{Cl})\end{array}$} \\
\hline & $\begin{array}{l}\text { Before } \\
\text { retirement }\end{array}$ & $\begin{array}{c}\text { After } \\
\text { retirement }\end{array}$ & \\
\hline \multicolumn{4}{|l|}{ Men } \\
\hline \multicolumn{4}{|l|}{ Antihypertensive medication } \\
\hline$<20$ & 3.0 & 4.4 & $1.50(1.09-2.07)$ \\
\hline$<30$ & 3.9 & 5.4 & $1.40(1.06-1.83)$ \\
\hline$<40$ & 5.6 & 7.2 & $1.32(1.03-1.68)$ \\
\hline$<50$ & 8.2 & 10.6 & $1.34(1.10-1.64)$ \\
\hline$<60$ & 12.0 & 14.5 & $1.26(1.05-1.50)$ \\
\hline$<70$ & 15.5 & 19.0 & $1.29(1.09-1.52)$ \\
\hline$<80$ & 19.9 & 24.1 & $1.29(1.11-1.49)$ \\
\hline \multicolumn{4}{|l|}{ Antidiabetic medication } \\
\hline$<20$ & 0.9 & 2.5 & $2.74(1.18-6.37)$ \\
\hline$<30$ & 1.4 & 4.4 & $3.45(1.92-6.18)$ \\
\hline$<40$ & 2.3 & 5.2 & $2.40(1.37-4.20)$ \\
\hline$<50$ & 3.9 & 7.0 & $1.88(1.03-3.44)$ \\
\hline$<60$ & 6.4 & 9.3 & $1.52(0.83-2.76)$ \\
\hline$<70$ & 9.7 & 12.9 & $1.38(0.87-2.19)$ \\
\hline$<80$ & 15.5 & 19.0 & $1.29(0.86-1.92)$ \\
\hline
\end{tabular}

Women

Antihypertensive medication

\begin{tabular}{rrrr|}
$<20$ & 2.7 & 3.9 & $1.48(1.20-1.84)$ \\
\hline$<30$ & 4.2 & 5.8 & $1.40(1.18-1.67)$ \\
\hline 40 & 6.1 & 7.5 & $1.25(1.07-1.46)$ \\
$<50$ & 9.7 & 11.2 & $1.17(1.03-1.33)$ \\
$<60$ & 14.0 & 15.7 & $1.15(1.03-1.28)$ \\
\hline$<70$ & 18.9 & 20.7 & $1.12(1.02-1.24)$ \\
\hline$<80$ & 23.8 & 25.5 & $1.10(1.00-1.20)$ \\
\hline Antidiabetic medication & & & \\
\hline$<20$ & 1.9 & 2.0 & $1.03(0.39-2.69)$ \\
\hline$<30$ & 3.1 & 3.0 & $0.97(0.44-2.12)$ \\
\hline$<40$ & 3.8 & 4.2 & $1.11(0.62-1.98)$ \\
$<50$ & 6.1 & 5.9 & $0.97(0.57-1.68)$ \\
\hline$<60$ & 10.0 & 9.2 & $0.92(0.58-1.46)$ \\
\hline$<70$ & 13.8 & 11.8 & $0.85(0.57-1.27)$ \\
\hline$<80$ & 20.1 & 16.6 & $0.80(0.56-1.14)$ \\
\hline
\end{tabular}

Note: $\mathrm{Cl}=$ confidence interval, $\mathrm{OR}=$ odds ratio.

*Odds ratio for poor adherence 1-4 years after retirement compared with 1-3 years before retirement derived from repeated-measures logistic regression generalized estimating equations adjusted for sex, age at retirement and calendar year. 
complications in overweight patients with type 2 diabetes (UKPDS 34). UK Prospective Diabetes Study (UKPDS) Group. Lancet 1998;352:854-65.

5. Cramer JA, Benedict A, Muszbek N, et al. The significance of compliance and persistence in the treatment of diabetes, hypertension and dyslipidaemia: a review. Int J Clin Pract 2008;62:76-87.

6. Vrijens B, Vincze G, Kristanto P, et al. Adherence to prescribed antihypertensive drug treatments: longitudinal study of electronically compiled dosing histories. BMJ 2008;336:1114-7.

7. DiMatteo MR. Variations in patients' adherence to medical recommendations: a quantitative review of 50 years of research. Med Care 2004;42:200-9.

8. DiMatteo MR, Giordani PJ, Lepper HS, et al. Patient adherence and medical treatment outcomes: a meta-analysis. Med Care 2002;40:794-811.

9. Simpson SH, Eurich DT, Majumdar SR, et al. A meta-analysis of the association between adherence to drug therapy and mortality. BMJ 2006;333:15.

10. Mazzaglia G, Ambrosioni E, Alacqua M, et al. Adherence to antihypertensive medications and cardiovascular morbidity among newly diagnosed hypertensive patients. Circulation 2009;120:1598-605.

11. Osterberg L, Blaschke T. Adherence to medication. N Engl J Med 2005;353:487-97.

12. Haynes RB, McKibbon KA, Kanani R. Systematic review of randomised trials of interventions to assist patients to follow prescriptions for medications. Lancet 1996;348:383-6.

13. Kripalani S, Yao X, Haynes RB. Interventions to enhance medication adherence in chronic medical conditions: a systematic review. Arch Intern Med 2007;167:540-50.

14. Westerlund H, Kivimaki M, Singh-Manoux A, et al. Self-rated health before and after retirement in France (GAZEL): a cohort study. Lancet 2009;374:1889-96.

15. Jokela M, Ferrie JE, Gimeno D, et al. From midlife to early old age: health trajectories associated with retirement. Epidemiology 2010;21:284-90.

16. Oksanen T, Vahtera J, Westerlund $\mathrm{H}$, et al. Is retirement beneficial for mental health? Longitudinal analysis of antidepressan use before and after retirement. Epidemiology 2011;22:553-9.

17. Kivimäki M, Hamer M, Batty GD, et al. Antidepressant medication use, weight gain and risk of type 2 diabetes mellitus: a population-based study. Diabetes Care 2010;33:2611-6.

18. Lau HS, de Boer A, Beuning KS, et al. Validation of pharmacy records in drug exposure assessment. J Clin Epidemiol 1997;50: 619-25.

19. Khan NA, Yun L, Humphries K, et al. Antihypertensive drug use and adherence after stroke: are there sex differences? Stroke 2010;41:1445-9.

20. Furu K, Wettermark B, Andersen M, et al. The Nordic countries as a cohort for pharmacoepidemiological research. Basic Clin Pharmacol Toxicol 2010;106:86-94.

21. Guidelines for ATC classification and DDD assignment. Oslo (Norway): World Health Centre Collaborating Centre for Drug Statistics Methodology; 2004.

22. Keskimäki I, Aro S. Accuracy of data on diagnosis, procedures and accidents in the Finnish Hospital Discharge Register. Int $J$ Health Sci 1991;2:15-21.

23. Rapola JM, Virtamo J, Korhonen P, et al. Validity of diagnoses of major coronary events in national registers of hospital diagnoses and deaths in Finland. Eur J Epidemiol 1997;13:133-8.
24. Mathers CD, Fat DM, Inoue M, et al. Counting the dead and what they died from: an assessment of the global status of cause of death data. Bull World Health Organ 2005;83:171-7.

25. Lipsitz SR, Kim K, Zhao L. Analysis of repeated categorical data using generalized estimating equations. Stat Med 1994; 13:1149-63.

26. Holt EW, Muntner P, Joyce C, et al. Life events, coping, and antihypertensive medication adherence among older adults: the cohort study of medication adherence among older adults. Am J Epidemiol 2012;176(Suppl 7):S64-71.

27. Krousel-Wood M, Joyce C, Holt E, et al. Predictors of decline in medication adherence: results from the cohort study of medication adherence among older adults. Hypertension 2011;58:804-10.

28. Goldman DP, Joyce GF, Zheng Y. Prescription drug cost sharing: associations with medication and medical utilization and spending and health. JAMA 2007;298:61-9.

Affiliations: Department of Epidemiology and Public Health (Kivimäki, Batty, Hamer), University College London, London, UK; Finnish Institute of Occupational Health and University of Helsinki (Kivimäki, Pentti, Oksanen, Virtanen, Vahtera), Helsinki, Finland; Centre for Cognitive Aging and Cognitive Epidemiology (Batty), University of Edinburgh, Edinburgh, UK; Institut national de la santé et de la recherche médicale (Nabi), Centre for Research in Epidemiology and Population Health, Villejuif, France; Department of Pharmacology (Korhonen, Huupponen), Drug Development and Therapeutics, University of Turku, and Turku University Hospital, Turku, Finland; Harvard School of Public Health (Kawachi), Boston, Mass.; Stress Research Institute (Westerlund), Stockholm University, Stockholm, Sweden; Department of Public Health (Vahtera), University of Turku, and Turku University Hospital, Turku, Finland

Contributors: Mika Kivimäki, Jussi Vahtera and Jaana Pentti designed the hypothesis. Mika Kivimäki wrote the first draft. Jussi Vahtera and Jaana Pentti analyzed the data. All of the authors contributed to the concept and design of the study and the critical revision of the manuscript for important intellectual content, and approved the final version submitted for publication.

Funding: This study was supported by the Academy of Finland, the Finnish Work Environment Fund, Finland, the Social Insurance Institution of Finland and the participating organizations. Mika Kivimäki was supported by the United Kingdom Medical Research Council (K013351), the National Institutes of Health (R01HL036310 and R01AG034454) of the United States, the Finnish Work Environment Fund, and an Economic and Social Research Council professorship, UK. David Batty was supported by a Wellcome Trust Research Fellowship. Mark Hamer was supported by the British Heart Foundation. The sponsors had no role in designing the study, analyzing or interpreting the data, or preparing the manuscript. 